\title{
Crescimento inicial de Campomanesia xanthocarpa O. Berg sob diferentes composições de substratos
}

\author{
CARNEVALI, T.O.'”; VIEIRA, M.C.1; LUCIANO, A.T.', GONÇALVES, W.V.'; RODRIGUES, W.B.'; RAMOS, \\ M.B.M. ${ }^{1}$ \\ Universidade Federal da Grande Dourados - UFGD/FCA, Rodovia Dourados - Itahum, Km 12 - S/N - Cidade \\ Universitária. Caixa Postal 533 - CEP: 79.804-970 - Dourados-MS - Brasil; E-mail: thiagocarnevali@live.com.
}

\begin{abstract}
RESUMO: O objetivo do trabalho foi avaliar a influência de diferentes composições de substratos no crescimento inicial de Campomanesia xanthocarpa, bem como avaliar índices fisiológicos. O trabalho foi desenvolvido em Dourados-MS, no período de janeiro a outubro de 2008. Foi estudada a Campomanesia xanthocarpa sob cinco diferentes substratos (LVd/A/ $\mathrm{O}=$ Latossolo Vermelho distroférrico+areia grossa lavada+Organosuper ${ }^{\circledast}(5: 4: 1 \mathrm{v} / \mathrm{v}) ; \mathrm{LVd} / \mathrm{A} /$ $\mathrm{C}=$ Latossolo Vermelho distroférrico+areia grossa lavada+cama-de-frango $(5: 4: 1 \mathrm{v} / \mathrm{v}) ; \mathrm{LVd} / \mathrm{A} /$ $\mathrm{O}^{2}=$ Latossolo Vermelho distroférrico+areia grossa lavada+Organosuper ${ }^{\circledR}(7: 2: 1 \mathrm{v} / \mathrm{v}) ; \mathrm{LVd} / \mathrm{A} /$ $\mathrm{C}^{2}=$ Latossolo Vermelho distroférrico+areia grossa lavada+cama-de-frango (7:2:1 v/v); LVd/A= Latossolo Vermelho distroférrico+areia grossa lavada (6:4 v/v)), em vasos de $7 \mathrm{dm}^{3}$, e mantidos em ambiente protegido com $100 \%$ de luminosidade. O substrato composto por Latossolo Vermelho distroférrico + areia grossa lavada proporcionou maior diâmetro de caule $(8,29 \mathrm{~mm})$, massa seca de raiz, caule e folhas $(6,98 ; 4,49$ e 9,06 g/planta, respectivamente) e aumento nos índices fisiológicos nas avaliações finais, indicando que este substrato pode ser utilizado no desenvolvimento de Campomanesia xanthocarpa.
\end{abstract}

Palavras-chaves: guabiroba, índices fisiológicos, cama-de-frango, Organosuperæ.

\begin{abstract}
Initial growth of Campomanesia xanthocarpa O. Berg under different substrate compositions. The objective of this study was to evaluate the influence of different compositions of substrates on the initial growth of Campomanesia xanthocarpa and to evaluate the physiological rate. The study was conduct in the city of Dourados - state of Mato Grosso do Sul, Brazil, in the period from January to October 2008. The Campomanesia xanthocarpa was studying under five different substrates $\left(\mathrm{LVd} / \mathrm{A} / \mathrm{O}=\right.$ Oxisol+coarse sand+Organosuper ${ }^{\circledR}(5: 4: 1$ $\mathrm{v} / \mathrm{v}) ; \mathrm{LVd} / \mathrm{A} / \mathrm{C}=$ Oxisol+ coarse sand+ chicken manure $(5: 4: 1 \mathrm{v} / \mathrm{v}) ; \mathrm{LVd} / \mathrm{A} / \mathrm{O}^{2}=$ Oxisol+ coarse sand+Organosuper ${ }^{\circledR}(7: 2: 1 \mathrm{v} / \mathrm{v}) ; \mathrm{LVd} / \mathrm{A} / \mathrm{C}^{2}=$ Oxisol+ coarse sand+chicken manure $(7: 2: 1 \mathrm{v} / \mathrm{v}) ; \mathrm{LVd} /$ $A=$ Oxisol+ coarse sand $(6: 4 \mathrm{v} / \mathrm{v}))$ in $7 \mathrm{dm}^{3}$ pots and kept in a protected environment with $100 \%$ brightness. The substrate consisting of Oxisol + coarse sand provided greater stem diameter $(8.29 \mathrm{~mm})$, dry weight of the root, stem and leaf $(6.98,4.49$ and $9.06 \mathrm{~g} /$ plant, respectively) and increased the physiological indices in the final evaluations, which indicates that this substrate can be used in the development of Campomanesia xanthocarpa.
\end{abstract}

Keywords: Campomanesia xanthocarpa, physiological rate, chicken manure, Organosuper .

\section{INTRODUÇÃO}

Campomanesia xanthocarpa Berg. (Myrtaceae), conhecida popularmente como guabiroba ou guavirova, é uma espécie frutífera nativa do Brasil de ampla ocorrência no Cerrado que pode atingir até 15 metros de altura. Possui folhagem verde escura, flores brancas que ocorrem de setembro a outubro e frutos de coloração verde a amarela quando maduro e em forma de bagas arredondadas (Lorenzi, 2008). Os frutos possuem alto teor de água (81,4\%); lipídios (1,9\%); carboidratos totais $(8,9 \%)$; fibra alimentar $(6,3 \%)$;

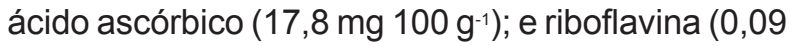

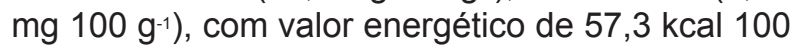
$\mathrm{g}^{-1}$ (Vallilo et al., 2008).

A espécie é conhecida por suas propriedades medicinais, usada popularmente como depurativa, antidiarreica, antirreumática e para diminuir o colesterol do sangue (Ballvé et al., 
1995). O extrato hidroalcoólico das folhas de $C$. xanthocarpa apresenta atividade antiulcerogênica, uma vez que, a administração oral do extrato na dose de $400 \mathrm{mg} \mathrm{kg}^{-1}$ promoveu efeito preventivo de úlcera gástrica em ratos e não produziu sintomas tóxicos em camundongos nas doses acima de $5 \mathrm{~g}$ $\mathrm{kg}^{-1}$ (Markman et al., 2004). Vinagre et al. (2010) sugerem que o tratamento com decocto das folhas de C. xanthocarpa (20 $\left.\mathrm{g} \mathrm{L}^{-1}\right)$ possa ser útil para o manejo do diabete melito. Klafke et al. (2010) relataram que o uso de cápsulas contendo folhas secas trituradas da C. xanthocarpa nas doses de 250 e $500 \mathrm{mg}$ reduziu o nível de colesterol LDL e total, além do estresse oxidativo do plasma em pacientes com hipercolesterolemia.

No entanto, as plantas são colhidas de forma extrativista, por não existir cultivo da espécie e por falta de informações na literatura sobre o seu cultivo. Dentre as técnicas utilizadas para a produção de mudas com maior qualidade destacase produção em diferentes substratos, o qual, pode proporcionar melhorias nas propriedades físicas e químicas do solo, resultando em maior desenvolvimento e sobrevivência quando levadas para campo. O uso de diferentes substratos em Campomanesia adamantium proporcionou aumento da emergência de plantas e do crescimento inicial. Carnevali et al. (2008) verificaram que houve maior emergência utilizando os substrato Plantmax ${ }^{\circledR}(94 \%)$ e Latossolo Vermelho distroférrico+areia+camade-frango (90\%), e maior índice de velocidade de emergência de 1,37 e 1,19 para os mesmos substratos, respectivamente. Costa et al., (2012) verificaram que a utilização de Organosuper ${ }^{\circledR}(80 \%)$ + Argissolo Vermelho Amarelo (20\%) proporcionou maior massa seca da parte aérea $(0,294 \mathrm{~g})$, massa seca de raiz $(0,169)$ e maior índice de qualidade de Dickson $(0,121)$ em ambiente protegido com $50 \%$ de luminosidade.

O desenvolvimento inicial de determinada espécie pode ser avaliado por várias técnicas, especialmente a análise de crescimento, pois visa estudar os efeitos do ambientais sobre o crescimento das plantas. Além disso, é uma ferramenta prática e precisa que permite inferir como os diferentes tratamentos afetam os processos fisiológicos da planta, permitindo logo no início do desenvolvimento, verificar quais fatores podem proporcionar maior rendimento da planta (Benincasa, 2003).

Sendo assim, o objetivo deste trabalho foi realizar analise de crescimento da Campomanesia xanthocarpa sob influência de diferentes composições de substratos.

\section{MATERIAL E MÉTODOS}

O trabalho foi desenvolvido no Horto de Plantas Medicinais - HPM (22'11'43.7'S e $\left.054^{\circ} 56^{\prime} 08.5^{\prime \prime} \mathrm{W}\right)$, da Universidade Federal da Grande Dourados - UFGD, em Dourados - MS, no período de janeiro a outubro de 2008. O clima, segundo a classificação de Köppen, é do tipo clima tropical com estação seca de inverno (Aw), com precipitação média anual de 1500 mm e temperatura média anual de $23,6^{\circ} \mathrm{C}$.

Foi estudada a guabiroba sob cinco diferentes substratos: $\mathrm{LVd} / \mathrm{A} / \mathrm{O}=$ Latossolo Vermelho distroférrico + areia grossa lavada + Organosupere $(5: 4: 1 \mathrm{v} / \mathrm{v}) ; \mathrm{LVd} / \mathrm{A} / \mathrm{C}=$ Latossolo Vermelho distroférrico + areia grossa lavada + cama-de-frango (5:4:1 $\mathrm{v} / \mathrm{v}) ; \mathrm{LVd} / \mathrm{A} / \mathrm{O}^{2}=$ Latossolo Vermelho distroférrico + areia grossa lavada + Organosuper ${ }^{\circledast}(7: 2: 1 \mathrm{v} / \mathrm{v})$; $\mathrm{LVd} / \mathrm{A} / \mathrm{C}^{2}=$ Latossolo Vermelho distroférrico + areia grossa lavada + cama-de-frango $(7: 2: 1 \mathrm{v} / \mathrm{v})$; $\mathrm{LVd} /$ $\mathrm{A}=$ Latossolo Vermelho distroférrico + areia grossa lavada (6:4 v/v). Os tratamentos foram arranjados no delineamento de blocos casualizados, com quatro repetições e a unidade experimental foi constituída de 10 vasos por parcela, com uma planta por vaso. O Latossolo Vermelho distroférrico utilizado para a composição dos substratos foi proveniente do horizonte $A$, e os atributos químicos e físicos dos diferentes substratos estão dispostas na Tabela 1 , determinados conforme metodologia da Silva et al. (2009).

A composição química do Organosuper ${ }^{\circledR}$ (composto orgânico produzido pela Empresa Organoeste, do MS) foi: $6,72 \%$ de N, $4,27 \%$ de $P$, $0,42 \%$ de $\mathrm{K}, 2,75 \%$ de $\mathrm{Ca}, 0,4 \%$ de $\mathrm{Mg}, 0,86 \%$ de $\mathrm{S}$, $0,02 \%$ de $\mathrm{Zn}, 0,003 \%$ de $\mathrm{Cu}, 0,04 \%$ de $\mathrm{Mn}, 1,39 \%$ de $\mathrm{Fe}, 0,27 \%$ de $\mathrm{Si}, 25,53 \%$ de C, $1,44 \%$ de $\mathrm{C}$ orgânico, $4 / 1$ relação $\mathrm{C} / \mathrm{N}, \mathrm{pH} 8,7,5 \%$ de umidade a $65^{\circ} \mathrm{C}$ e $45,96 \%$ de matéria orgânica total. A composição química da cama-de-frango, base palha de arroz, usada foi: $2,05 \%$ de $\mathrm{C}$ orgânico; $3,13 \%$ de $\mathrm{P}$ total; $2,85 \%$ de $\mathrm{K}$ total; $2,43 \%$ de $\mathrm{N}$ total; $0,18 \%$ de $\mathrm{Ca}$ total, $0,09 \%$ de $\mathrm{Mg}$ total e relação $\mathrm{C} / \mathrm{N}$ de 10,99 .

As sementes da guabiroba foram colhidas de área nativas de Dourados. As plantas foram identificadas e depositadas no Herbário DDMS, sob número 952. As sementes foram semeadas em bandejas de poliestireno expandido de 72 células com substrato Bioplant ${ }^{\oplus}$, mantidas em ambiente protegido com sombrite $50 \%$ de luminosidade, com irrigações diárias. Aos 45 dias após semeio as plantas alcançaram em torno de $10 \mathrm{~cm}$ de altura, e foram transplantadas para vasos de $7 \mathrm{dm}^{3}$ conforme os respectivos tratamentos e mantidos em ambiente protegido em pleno sol. Foram realizadas irrigações em turnos de 2 dias para reposição da água em todo o período experimental, objetivando-se $70 \%$ da capacidade de campo.

A partir de 18 até 180 dias do transplante (DAT), com intervalos de 18 dias, mediu-se a altura

Rev. Bras. PI. Med., Campinas, v.17, n.2, p.316-323, 2015. 
TABELA 1. Análise química e física dos substratos utilizados no desenvolvimento inicial da guabiroba. Dourados, 2008.

\begin{tabular}{|c|c|c|c|c|c|}
\hline \multicolumn{6}{|c|}{ Atributos Químicos } \\
\hline Atributos & $\mathrm{LVd} / \mathrm{A} / \mathrm{O}$ & $\mathrm{LVd} / \mathrm{A} / \mathrm{C}$ & $\mathrm{LVd} / \mathrm{A} / \mathrm{O}^{2}$ & $\mathrm{LVd} / \mathrm{A} / \mathrm{C}^{2}$ & $\mathrm{LVd} / \mathrm{A}$ \\
\hline $\mathrm{pH} \mathrm{CaCl}{ }_{2}$ & 6,84 & 6,91 & 6,77 & 6,80 & 4,45 \\
\hline $\mathrm{pH} \mathrm{H}_{2} \mathrm{O}$ & 7,48 & 7,65 & 7,50 & 7,41 & 5,31 \\
\hline$P\left(\mathrm{mg} \mathrm{dm}^{-3}\right)$ & 66,01 & 247,04 & 34,26 & 219,16 & 0,56 \\
\hline $\mathrm{K}\left(\mathrm{cmol}_{\mathrm{c}} \mathrm{dm}^{-3}\right)$ & 6,12 & 9,54 & 6,99 & 8,36 & 0,97 \\
\hline $\mathrm{Al}\left(\mathrm{cmol}_{\mathrm{c}} \mathrm{dm}^{-3}\right)$ & 0,00 & 0,00 & 0,00 & 0,00 & 6,00 \\
\hline $\mathrm{Ca}\left(\mathrm{cmol}_{\mathrm{c}} \mathrm{dm}^{-3}\right)$ & 46,17 & 54,13 & 51,04 & 72,47 & 23,53 \\
\hline $\mathrm{Mg}\left(\mathrm{cmol}_{\mathrm{c}} \mathrm{dm}^{-3}\right)$ & 20,26 & 33,57 & 23,03 & 38,55 & 8,43 \\
\hline $\mathrm{H}+\mathrm{Al}\left(\mathrm{cmol}_{\mathrm{c}} \mathrm{dm}^{-3}\right)$ & 9,92 & 10,57 & 11,51 & 13,22 & 15,67 \\
\hline Soma de bases $\left(\mathrm{cmol}_{\mathrm{c}} \mathrm{dm}^{-3}\right)$ & 72,55 & 97,24 & 81,06 & 119,38 & 32,93 \\
\hline Capacidade de troca de cátions $\left(\mathrm{cmol}_{\mathrm{c}} \mathrm{dm}^{-3}\right)$ & 82,47 & 107,81 & 92,57 & 132,60 & 48,60 \\
\hline Saturação por bases (\%) & 87,97 & 90,19 & 87,56 & 90,03 & 67,76 \\
\hline Matéria orgânica $\left(\mathrm{g} \mathrm{kg}^{-1}\right)$ & 13,5 & 14,3 & 17,9 & 19,1 & 8,2 \\
\hline \multicolumn{6}{|c|}{ Atributos físicos } \\
\hline Densidade (úmida) de volume $\left(\mathrm{g} \mathrm{cm}^{-3}\right)$ & 0,06 & 0,08 & 0,11 & 0,08 & 0,09 \\
\hline Densidade de partícula $\left(\mathrm{g} \mathrm{cm}^{-3}\right)$ & 0,82 & 0,95 & 0,92 & 0,94 & 0,95 \\
\hline Porosidade total $(\%)$ & 64,33 & 22,81 & 39,16 & 15,62 & 32,98 \\
\hline Areia $(\%)$ & 65,37 & 50,35 & 33,71 & 30,84 & 34,29 \\
\hline Argila (\%) & 28,34 & 30,08 & 39,38 & 45,46 & 24,89 \\
\hline Silte (\%) & 6,28 & 19,56 & 26,90 & 23,69 & 40,81 \\
\hline
\end{tabular}

$\mathrm{LVd} / \mathrm{A} / \mathrm{O}=$ Latossolo Vermelho distroférrico + areia grossa lavada + Organosuper ${ }^{\circledR} ; \mathrm{LVd} / \mathrm{A} / \mathrm{C}=$ Latossolo Vermelho distroférrico + areia grossa lavada + cama-de-frango; $\mathrm{LVd} / \mathrm{A} / \mathrm{O}^{2}=$ Latossolo Vermelho distroférrico + areia grossa lavada + Organosuper ${ }^{\otimes} \mathrm{LVd} / \mathrm{A} / \mathrm{C}^{2}=\mathrm{Latossolo} V \mathrm{Vermelho}$ distroférrico + areia grossa lavada + cama-de-frango; LVd/A= Latossolo Vermelho distroférrico + areia grossa lavada.

de plantas, desde o nível do solo no vaso até a inflexão da folha mais alta e o diâmetro do caule $( \pm$ $1,0 \mathrm{~cm}$ acima do nível do solo no vaso) de todas as plantas das parcelas.

A partir de 90 até 180 DAT, foram colhidas, em intervalos de 30 dias, duas plantas por parcela. Os órgãos das plantas foram separados e avaliados quanto ao comprimento da maior de raiz e ao diâmetro da raiz, $\pm 2 \mathrm{~cm}$ abaixo do coleto, massas secas de raiz, caule, folhas e total, área foliar $\left(\mathrm{dm}^{2}\right)$, medida em integrador LI 3000. Para a obtenção da massa seca, utilizou-se estufa com circulação de ar forçada a $60 \pm 5^{\circ} \mathrm{C}$, até obtenção de massa constante. Com base nos resultados de massa seca acumulada e área foliar, foram determinadas a taxa de crescimento absoluto (TCA), taxa de crescimento relativo (TCR) e a taxa assimilatória líquida ( $T A L)$ (Benincasa, 2003):

$\mathrm{TCA}=(\mathrm{Pn}-\mathrm{Pn}-1) /(\mathrm{Tn}-\mathrm{Tn}-1)$, onde:

$\mathrm{Pn}=$ a massa seca total até

$\mathrm{Pn}-1$ = biomassa seca acumulada até $\mathrm{n}-1$,

Tn = número de dias após a emergência, por ocasião da avaliação $n$,

$\mathrm{Tn}-1$ = é o número de dias após a emergência, por ocasião da avaliação n-1.

TCR $=(\ln P n-\operatorname{InPn}-1) /(T n-T n-1)$, onde:

$\operatorname{lnPn}=$ logaritmo natural da massa seca total

até a avaliação $n$, $\ln P n-1$ = biomassa seca acumulada até a avaliação n-1.

$\mathrm{TAL}=[(\mathrm{Pn}-\mathrm{Pn}-1) /(\mathrm{Tn}-\mathrm{Tn}-1)] \cdot[(\ln A n-\operatorname{InAn}-1) /$

(An-An-1)], onde:

In = logaritmo natural;

$\mathrm{An}=$ área foliar da planta, por ocasião da avaliação $n$,

An-1 =é a área foliar da planta, por ocasião da avaliação n-1.

Os dados de altura de plantas, diâmetro do caule, comprimento de raiz, diâmetro de raiz, área foliar e massa seca total foram submetidos à análise da correlação de Pearson. Os dados de crescimento e os índices fisiológicos foram submetidos à análise de variância. Quando houve significância pelo teste $F$, as médias foram submetidas ao teste de Tukey ou à análise de regressão, todos até $5 \%$ de probabilidade.

\section{RESULTADOS E DISCUSSÃO}

A altura de plantas, diâmetro do caule, comprimento e diâmetro de raiz, acúmulo de massa seca e área foliar das mudas de guabiroba foram influenciados significativamente pela interação entre tipos de substratos e épocas de avaliação (Figura 1,2 e 3). A maior altura $(29,59 \mathrm{~cm}$ aos 180 DAT) foi obtida utilizando o substrato $\mathrm{LVd} / \mathrm{A} / \mathrm{O}$, seguido pelo 
tratamento $\mathrm{LVd} / \mathrm{A} / \mathrm{O}^{2}$ que proporcionou maior altura de $26,10 \mathrm{~cm}$ (Figura $1 \mathrm{a}$ ). Ambos os tratamentos continham Organosuper ${ }^{\circledR}$ que apresenta em sua composição química maior teor de nitrogênio e relação $\mathrm{C} / \mathrm{N}$ mais baixa em comparação com a cama-de-frango, o que pode ter influenciado o maior crescimento da parte aérea da planta. O nitrogênio atua no crescimento da parte aérea, estimula um crescimento mais vigoroso e prolonga o período vegetativo (Ghorbani et al., 2008) por estar envolvido no metabolismo vegetal, participando como constituinte de moléculas de proteínas, coenzimas, ácidos nucleicos, clorofila e outras enzimas, controlando o desenvolvimento das plantas.

Resultado similar foi observado por Costa et al. (2012), em que o substrato composto por $80 \%$ de Argissolo Vermelho Amarelo e $20 \%$ de Organosuper ${ }^{\circledR}$ proporcionou maior altura $(43,4 \mathrm{~cm})$ de mudas de tamarindo (Tamarindus indica) aos 170 dias após semeio em estufa a $100 \%$ de luminosidade. Isso sugere que a utilização de Organosuper ${ }^{\circledR}$ na composição do substrato aumenta o crescimento de diferentes espécies vegetais.

O maior diâmetro do caule $(8,29 \mathrm{~mm}$ aos 180 DAT; Figura 1 b) das mudas de guabiroba foi obtido utilizando o substrato LVd/A, com o qual houve aumento de $32 \%$ no diâmetro do caule em relação ao $\mathrm{LVd} / \mathrm{A} / \mathrm{C}$ e $24 \%$ em relação ao $\mathrm{LVd} / \mathrm{A} /$ $\mathrm{C}^{2}$. O maior desenvolvimento do diâmetro do caule foi obtido com a utilização do substrato que não possuía em sua composição o composto orgânico incorporado e menor teor de matéria orgânica (Tabela 1) indicando que a espécie se desenvolve adequadamente com nível abaixo de $1 \%$ de matéria orgânica no solo.

O maior comprimento da maior raiz $(31,73$
A

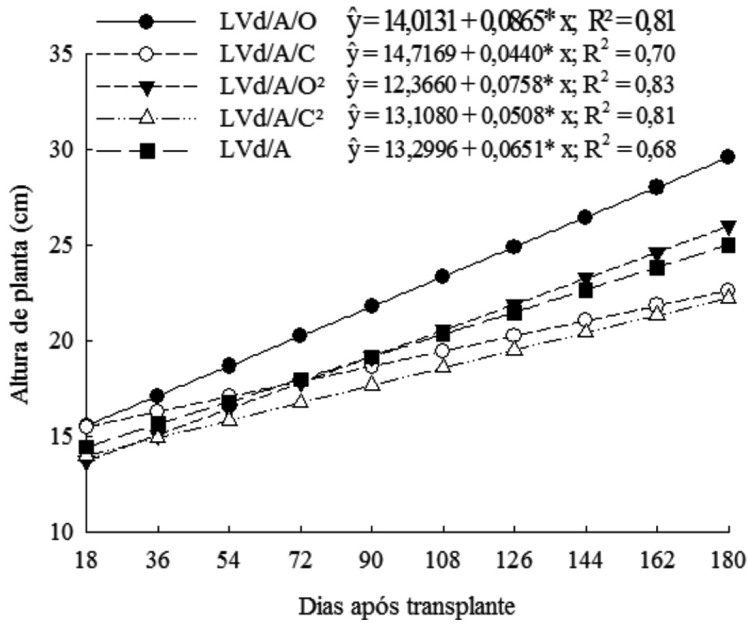

C

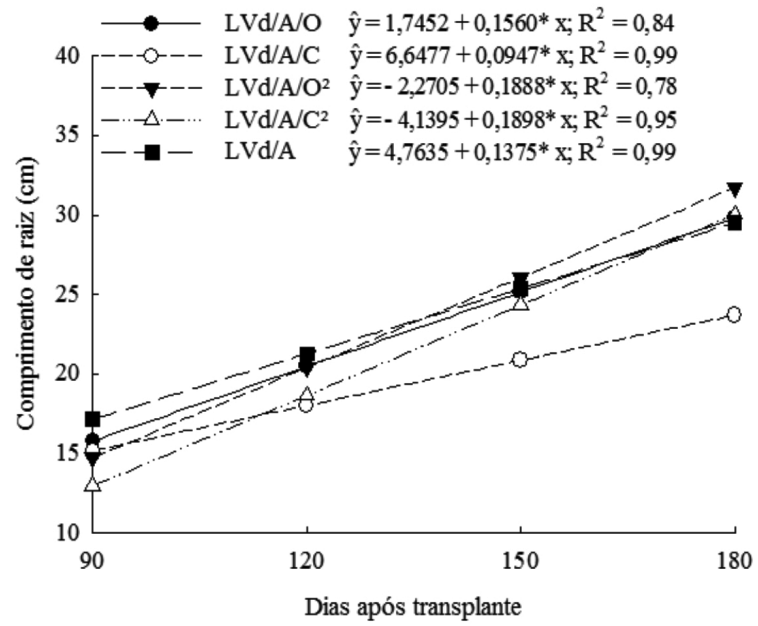

B

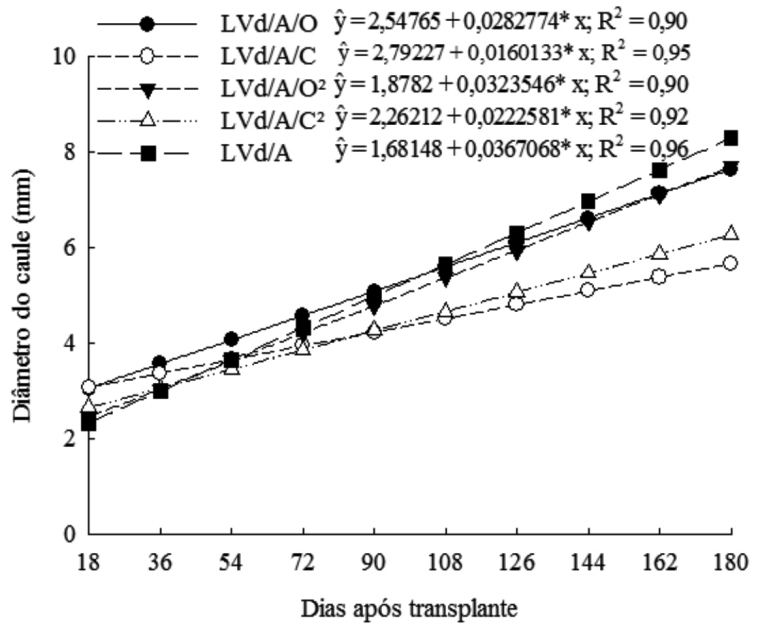

D

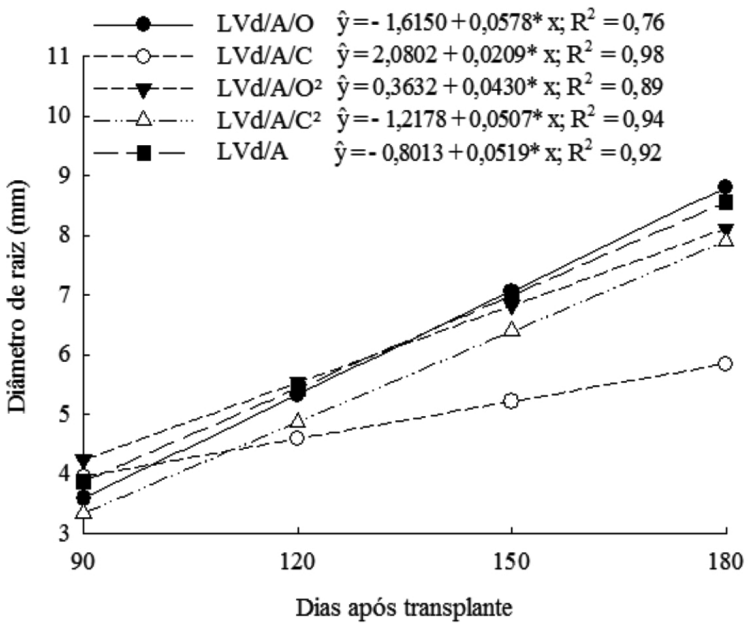

FIGURA 1. Altura de plantas (a), diâmetro do caule (b), comprimento da raiz (c) e diâmetro da raiz (d) de plantas da guabiroba cultivada com cinco substratos. Dourados, 2008. *significativo a $5 \%$ pelo teste T. LVd/A/ $\mathrm{O}=$ Latossolo Vermelho distroférrico + areia grossa lavada + Organosuper $\odot ; \mathrm{LVd} / \mathrm{A} / \mathrm{C}=$ Latossolo Vermelho distroférrico + areia grossa lavada + cama-de-frango; $\mathrm{LVd} / \mathrm{A} / \mathrm{O}^{2}=$ Latossolo Vermelho distroférrico + areia grossa lavada + Organosuper ${ }^{\oplus} \mathrm{LVd} / \mathrm{A} / \mathrm{C}^{2}=$ Latossolo Vermelho distroférrico + areia grossa lavada + cama-de-frango; $\mathrm{LVd} / \mathrm{A}=$ Latossolo Vermelho distroférrico + areia grossa lavada. 
$\mathrm{cm}$ ) foi obtido no tratamento $\mathrm{LVd} / \mathrm{A} / \mathrm{C}^{2}$ aos $180 \mathrm{DAT}$ (Figura $1 \mathrm{c}$ ). O maior diâmetro da maior raiz (Figura 1 d) foi observado no tratamento $\mathrm{LVd} / \mathrm{A} / \mathrm{O}$ de 8,80 $\mathrm{mm}$, aos 180 DAT. Nota-se que o maior comprimento e o maior diâmetro da maior raiz foi observado com a utilização de Organosuper ${ }^{\circledR}$ na composição dos substratos, que promoveu melhoria física dos substratos (Tabela 1) principalmente na porosidade total, permitindo ao órgão maior exploração do solo.

O substrato LVd/A proporcionou maior produção de massa seca de raiz $(6,99 \mathrm{~g})$, caule $(4,50 \mathrm{~g})$, folhas $(9,07 \mathrm{~g})$ e total $(20,55 \mathrm{~g})$, aos 180 DAT (Figura 2). O tratamento sem a incorporação de resíduo orgânico proporcionou incremento de $72 \%(5,06 \mathrm{~g})$ para massa seca de raiz, $51 \%(2,33 \mathrm{~g})$ para massa seca de caule, $59 \%(5,7 \mathrm{~g})$ para massa seca de folhas e $62 \%(12,8 \mathrm{~g})$ para massa seca total de plantas em relação ao $\mathrm{LVd} / \mathrm{A} / \mathrm{C}$, que promoveu menor crescimento das características avaliadas.
Observa-se que os resíduos orgânicos utilizados não surtiram o efeito esperado de aumento da biomassa de planta, visto que todos foram inferiores ao substrato sem resíduo orgânico. $\mathrm{Na}$ avaliação dos dados referentes a análise de solo (Tabela 1), verifica-se que a incorporação de resíduos aumentou indiretamente o $\mathrm{pH}$ do solo, fato que não ocorreu sem a incorporação. O substrato LVd/A está mais ácido que os demais, indicando que a planta tem maior desenvolvimento em $\mathrm{pH}$ levemente ácido, em torno de 5,5. Nessa faixa de $\mathrm{pH}$ a disponibilidade de nutrientes é maior (Taiz e Zeiger, 2012) o que pode ter balanceado a disponibilidade de macro e micronutrientes necessário ao desenvolvimento da planta.

Costa et al. (2011) também verificaram que o Organosuper ${ }^{\circledR}$ elevou o $\mathrm{pH}$, o teor de matéria orgânica e nutrientes nos substratos, porém, as maiores massas secas observadas foram sem a
A

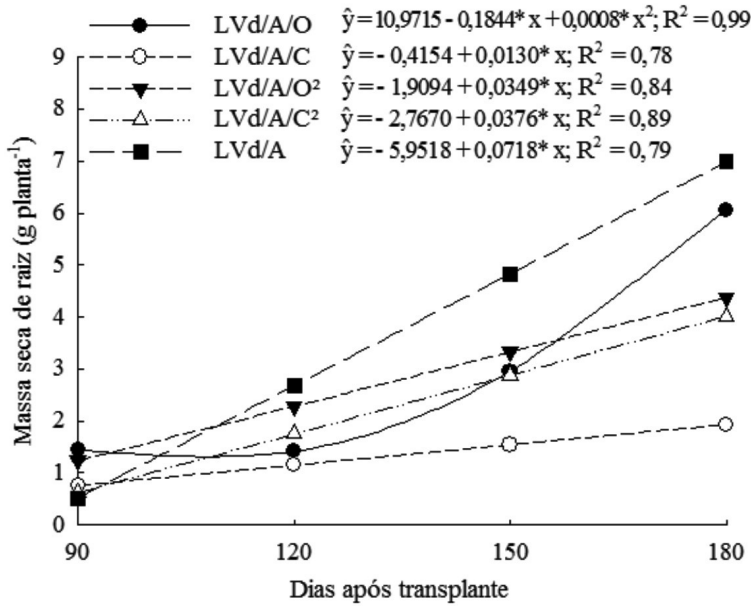

C

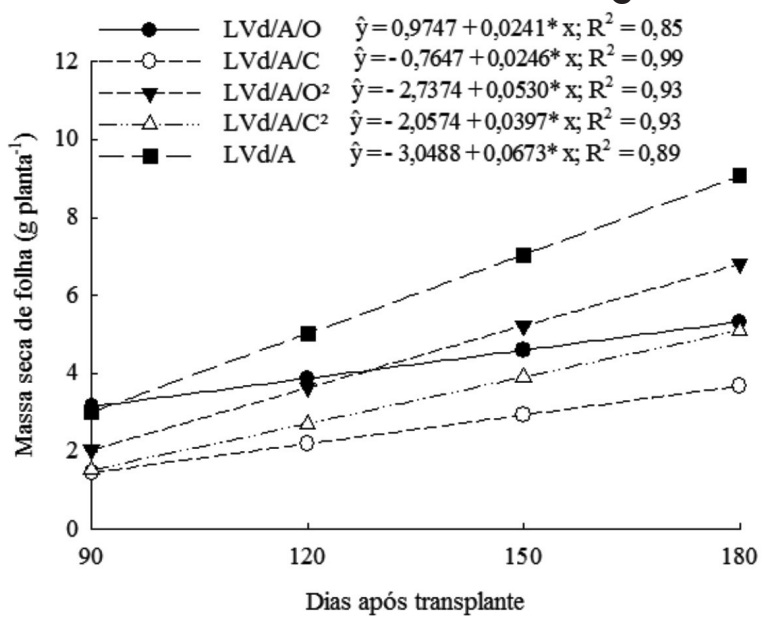

B

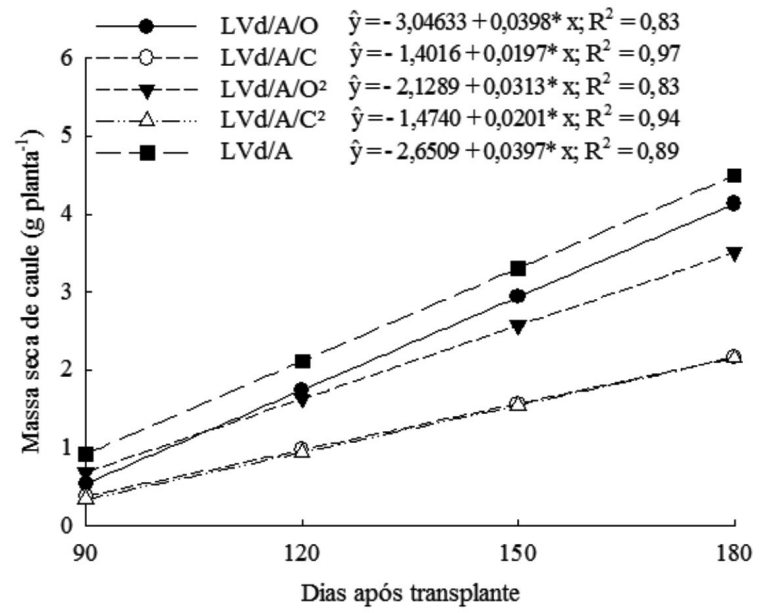

D

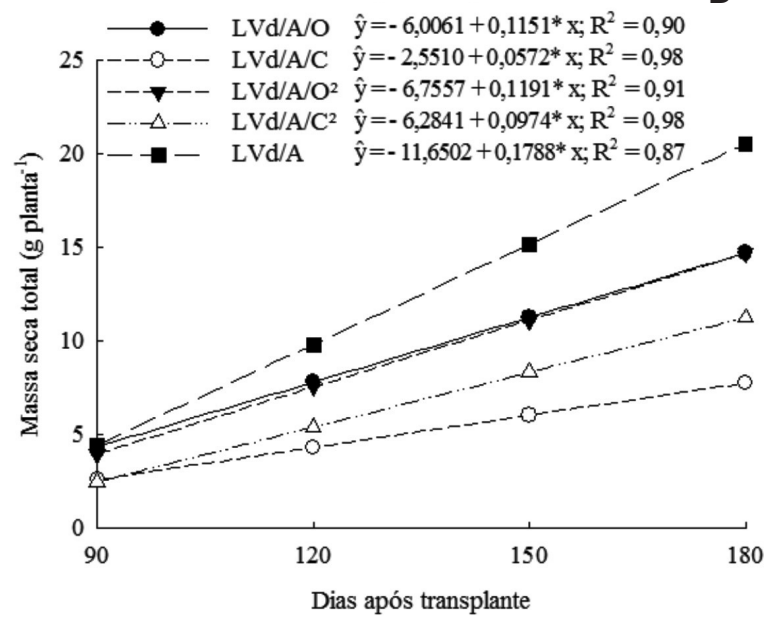

FIGURA 2. Massa seca de raiz (a), caule (b), folhas (c) e total (d) de plantas da guabiroba em função de diferentes substratos. Dourados, 2008. *significativo a $5 \%$ pelo teste $\mathrm{T}$.

$\mathrm{LVd} / \mathrm{A} / \mathrm{O}=$ Latossolo Vermelho distroférrico + areia grossa lavada + Organosuper ${ }^{\circ}$ LVd/A/C= Latossolo Vermelho distroférrico + areia grossa lavada + cama-de-frango; $\mathrm{LVd} / \mathrm{A} / \mathrm{O}^{2}=$ Latossolo Vermelho distroférrico + areia grossa lavada + Organosuper ${ }^{\oplus}$ : $\mathrm{LVd} / \mathrm{A} / \mathrm{C}^{2}=$ Latossolo Vermelho distroférrico + areia grossa lavada + cama-de-frango; $\mathrm{LVd} / \mathrm{A}=$ Latossolo Vermelho distroférrico + areia grossa lavada. 
utilização do composto orgânico incorporado ao substrato em mudas de mamão (Carica papaya) cultivadas em sacos de polietileno $15,0 \times 21,5$ cm (LXA) em ambiente protegido com $100 \%$ de luminosidade.

O substrato $\mathrm{LVd} / \mathrm{A} / \mathrm{O}$ proporcionou maior área foliar, de 167,9 dm², aos 180 DAT (Figura 3 ), representando $57 \%\left(97,3 \mathrm{dm}^{2}\right)$ de aumento em relação ao $\mathrm{LVd} / \mathrm{A} / \mathrm{C}^{2}$. Por apresentar menor relação $\mathrm{C} / \mathrm{N}$ e maior teor de $\mathrm{N}$, o Organosuperø possivelmente se sobressaiu em relação à camade-frango, disponibilizando mais nitrogênio para as plantas, que atua diretamente no processo de divisão e expansão celular, proporcionando maior crescimento e desenvolvimento da planta e contribuindo para maior índice de área foliar (Malavolta et al., 2006).

A altura e o diâmetro apresentaram alta correlação $(0,83)$ com a produção de massa seca total (Tabela 2), no entanto a correlação entre diâmetro e massa seca total $(0,90)$ foi maior do que para altura de planta $(0,78)$. Deste modo, podese inferir para essa espécie, que quanto maior o diâmetro do caule maior será produção de massa seca. O diâmetro do caule está relacionado com o acúmulo de fotoassimilados pela planta que são armazenados principalmente em tecidos de reservas, presentes no caule e na raiz, que poderão ser utilizados quando o ambiente possuir algum fator limitante a sobrevivência da planta.
O comprimento e diâmetro de raiz apresentaram alta correlação com a área foliar $(0,81$ e 0,87 , respectivamente), no entanto, houve baixa correlação da área foliar com as demais características, tais como massa seca, altura de plantas e diâmetro do caule (Tabela 2). Neste sentido, dentre as características mais importantes a ser avaliada no crescimento inicial da guabiroba destacam-se: a massa seca, a altura de plantas e o diâmetro do caule que se correlacionam mais fortemente.

A TCA, a TCR e a TAL foram influenciadas significativamente pela interação entre tipos de substratos e épocas de avaliação. Observam-se que não houve diferença estatística nos valores da TCA aos 120 DAT (Tabela 3), para as avaliações aos 150 DAT, o substrato LVd/A começa a se destacar dos outros substratos, apresentando diferença estatística para os substratos $\mathrm{LVd} / \mathrm{A} / \mathrm{C}$ e $\mathrm{LVd} / \mathrm{A} / \mathrm{O}^{2}$. Aos 180 DAT o substrato LVd/A se diferencia dos outros substratos apresentando maior TCA. Isso evidencia que com o passar do tempo o substrato LVd/A propiciou maior velocidade de crescimento das plantas.

Observa-se que para TCR, aos 120 DAT, os substratos compostos por LVd/A/C, LVd/A/O² e $\mathrm{LVd} / \mathrm{A} / \mathrm{C}^{2}$ apresentaram diferença significativa para os substratos LVd/A e LVd/A/O (Tabela 3). No entanto, nota-se que com o passar do tempo (150 e 180 DAT) não há diferença entre os substratos, mas

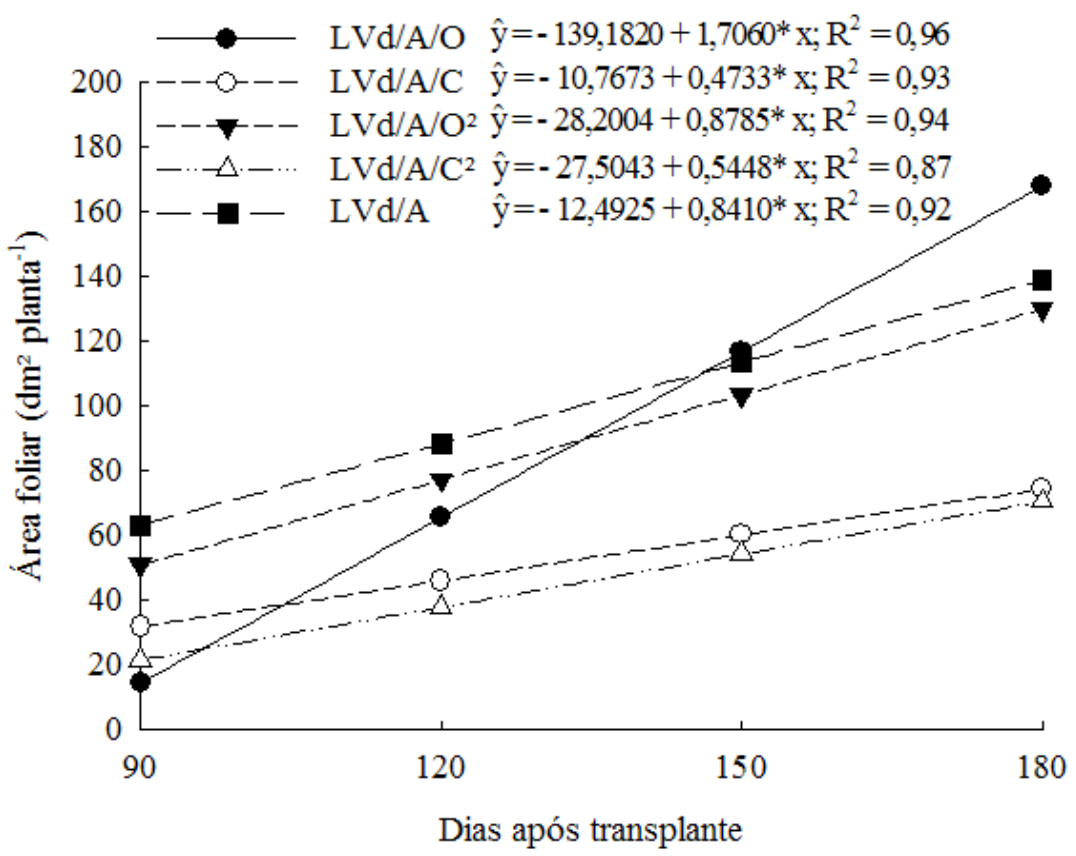

FIGURA 3. Área foliar de plantas de guabiroba em função de diferentes substratos. Dourados, 2008. *significativo a $5 \%$ pelo teste $\mathrm{T}$. LVd/A/O= Latossolo Vermelho distroférrico + areia grossa lavada + Organosuper ; LVd/A/ $\mathrm{C}=$ Latossolo Vermelho distroférrico + areia grossa lavada + cama-de-frango; $\mathrm{LVd} / \mathrm{A} / \mathrm{O}^{2}=$ Latossolo Vermelho distroférrico + areia grossa lavada + Organosuper ${ }^{\circledR} ; \mathrm{LVd} / \mathrm{A} / \mathrm{C}^{2}=$ Latossolo Vermelho distroférrico + areia grossa lavada + cama-de-frango; LVd/A= Latossolo Vermelho distroférrico + areia grossa lavada. 
TABELA 2. Análise da correlação de Pearson para altura de plantas $(\mathrm{cm})$, diâmetro do caule $(\mathrm{mm})$, comprimento da raiz $(\mathrm{cm})$, diâmetro da raiz $(\mathrm{mm})$, área foliar $\left(\mathrm{dm}^{3}\right)$ e produção de massa seca total $(\mathrm{g})$ de plantas de guabiroba em função de diferentes substratos. Dourados, 2008.

\begin{tabular}{lcccccc}
\hline Características & $\begin{array}{c}\text { Altura de } \\
\text { plantas }\end{array}$ & $\begin{array}{c}\text { Diâmetro } \\
\text { do caule }\end{array}$ & $\begin{array}{c}\text { Comprimento } \\
\text { de raiz }\end{array}$ & $\begin{array}{c}\text { Diâmetro de } \\
\text { raiz }\end{array}$ & $\begin{array}{c}\text { Área } \\
\text { foliar }\end{array}$ & $\begin{array}{c}\text { Massa seca } \\
\text { total }\end{array}$ \\
\hline Altura de plantas & & $0,83^{* *}$ & 0,21 & 0,17 & 0,03 & $0,78^{* *}$ \\
Diâmetro do caule & & & 0,19 & 0,17 & 0.00 & $0,90^{* *}$ \\
Comprimento de raiz & & & $0,95^{* *}$ & $0,81^{* *}$ & 0,29 \\
Diâmetro de raiz & & & & $0,87^{* *}$ & 0,28 \\
Área foliar & & & & & 0,14 \\
Massa seca total & & & & & \\
\hline
\end{tabular}

** significativo a $1 \%$ de probabilidade pelo Teste $\mathrm{t}$.

apenas entre as avaliações, isso evidencia que com o passar do tempo a taxa de crescimento da planta não depende do substrato onde ela é cultivada, mas apenas de atender as necessidades metabólicas do material já existente (Benincasa, 2003).

Os maiores valores da TAL foram observados com a utilização do substrato LVd/A/ $\mathrm{C}^{2}$ nas avaliações aos 120 e 150 DAT (Tabela 3), porém, aos 180 DAT o substrato LVd/A proporcionou maior TAL, indicando alta capacidade fotossintética da planta nos estádios de maior desenvolvimento.

Os índices fisiológicos em conjunto explicam que os incrementos foram homogêneos ao longo das avaliações no substrato $L V d / A$, o que não ocorreu com os demais substratos. $\mathrm{O}$ pH exerce papel determinante na disponibilidade de nutrientes no solo, o que possivelmente influenciou no acúmulo de biomassa.

O presente estudo permitiu concluir que a avaliação da altura de plantas, do diâmetro do caule e da massa seca são parâmetros eficientes na avaliação do desenvolvimento de mudas de guabiroba. Adicionalmente, o substrato composto por Latossolo Vermelho distroférrico + areia grossa lavada promoveu maior acumulo de biomassa seca das diferentes partes das plantas e maior diâmetro do caule aos 180 dias após transplante. A TCA, a TCR e a TAL apresentaram a tendência do do crescimento vegetal o longo do tempo, sendo destacada a TCA e a TAL aos 180 DAT, o que propiciou maior valores utilizando o substrato Latossolo Vermelho distroférrico + areia grossa

TABELA 3. Índices fisiológicos da guabiroba em função de diferentes substratos. Dourados, 2008.

\begin{tabular}{|c|c|c|c|c|c|}
\hline \multirow{2}{*}{ Dias após transplante } & \multicolumn{5}{|c|}{ Taxa de crescimento absoluto (TCA) } \\
\hline & LVd/A/O & LVd/A/C & $\mathrm{LVd} / \mathrm{A} / \mathrm{O}^{2}$ & LVd/A/C ${ }^{2}$ & LVd/A \\
\hline 90 & - & - & - & - & - \\
\hline 120 & $0,0246 \mathrm{aB}$ & $0,0763 \mathrm{aA}$ & $0,1085 \mathrm{aB}$ & $0,0731 \mathrm{aA}$ & $0,0390 \mathrm{aC}$ \\
\hline 150 & $0,1227 a b A$ & $0,0429 \mathrm{bA}$ & $0,0458 \mathrm{bB}$ & $0,0929 a b A$ & $0,1630 \mathrm{aB}$ \\
\hline 180 & $0,1956 \mathrm{bA}$ & $0,0573 \mathrm{cA}$ & $0,2276 \mathrm{bA}$ & $0,1276 \mathrm{bcA}$ & 0,3397 aA \\
\hline \multicolumn{6}{|l|}{ C.V.(\%): 44,84} \\
\hline & \multicolumn{5}{|c|}{ Taxa de crescimento relativo (TCR) } \\
\hline 90 & - & - & - & - & - \\
\hline 120 & $0,0040 \mathrm{bB}$ & 0,0220 aA & $0,0184 \mathrm{aA}$ & 0,0191 aA & $0,0053 \mathrm{bB}$ \\
\hline 150 & 0,0143 aA & $0,0086 \mathrm{aB}$ & $0,0054 \mathrm{aB}$ & 0,0143 aA & 0,0161 aA \\
\hline 180 & $0,0156 \mathrm{aA}$ & $0,0083 a B$ & $0,0182 \mathrm{aA}$ & $0,0134 \mathrm{aA}$ & $0,0196 \mathrm{aA}$ \\
\hline \multicolumn{6}{|l|}{ C.V.(\%): 43,16} \\
\hline & \multicolumn{5}{|c|}{ Taxa assimilatória líquida (TAL) } \\
\hline 90 & - & - & - & - & - \\
\hline 120 & $0,0006 \mathrm{bA}$ & $0,0021 \mathrm{aA}$ & $0,0017 \mathrm{abAB}$ & $0,0023 a A$ & $0,0005 \mathrm{bB}$ \\
\hline 150 & $0,0015 a b A$ & $0,0008 \mathrm{abB}$ & $0,0005 \mathrm{bB}$ & $0,0021 \mathrm{aA}$ & $0,0016 a b A B$ \\
\hline 180 & $0,0014 \mathrm{abA}$ & $0,0008 \mathrm{bB}$ & $0,0019 a b A$ & $0,0022 \mathrm{abA}$ & 0,0026 aA \\
\hline
\end{tabular}

C.V.(\%): 48,36

Médias seguidas pela mesma letra, minúscula na linha, maiúscula na coluna não diferem entre si pelo teste Tukey a $5 \%$ de probabilidade. $\mathrm{LVd} / \mathrm{A} / \mathrm{O}=$ Latossolo Vermelho distroférrico + areia grossa lavada + Organosuper ${ }^{\circledR}$ L LVd/A/C= Latossolo Vermelho distroférrico + areia grossa lavada + cama-de-frango; $\mathrm{LVd} / \mathrm{A} / \mathrm{O}^{2}=$ Latossolo Vermelho distroférrico + areia grossa lavada + Organosuper $; \mathrm{LVd} / \mathrm{A} / \mathrm{C}^{2}=\mathrm{Latossolo}$ Vermelho distroférrico + areia grossa lavada + cama-de-frango; LVd/A= Latossolo Vermelho distroférrico + areia grossa lavada. 
lavada sendo este substrato recomentado para o cultivo da espécie em vasos.

\section{AGRADECIMENTOS}

À FUNDECT-MS, ao CNPq e CAPES, pelas bolsas concedidas e apoio financeiro. E a Empresa Organoeste, do MS, pela doação do composto orgânico Organosuper®.

\section{REFERÊNCIAS}

BALLVÉ, A.C.; SIQUEIRA, N.C.S.; MENTZ, L.A.; SILVA, G.A.B; JOSÉ, K.F.D. Plantas medicinais de uso popular: Atlas Farmacognóstico. Canoas: Editora da ULBRA, 1995. 208p.

BENINCASA, M.M.P. Análise de crescimento de plantas (noções básicas). Jaboticabal: FUNEP. 2003. $41 \mathrm{p}$.

CARNEVALI, T.O.; RAMOS, D.D.; VIEIRA, M.C.; HEREDIA ZÁRATE, N.A.; SOUZA, N.H.; DOFINGER, A.M.V. Substratos na emergência de sementes de guavira (Campomanesia adamantium, Myrtaceae). In: Congresso Brasileiro de Olericultura, 48., 2008, Maringá. Anais... Maringá: CBO, 2008.

COSTA, E.; FERREIRA, A.F.A.; SILVA, P.N.L.; NARDELLI, E.M.V. Diferentes composições de substratos e ambientes protegidos na formação de mudas de pé-franco de tamarindeiro. Revista Brasileira de Fruticultura, Jaboticabal, v.34, n.4, p.1189-1198, 2012. COSTA, E.; LEAL, P.A.M; MESQUITA, V.A.G; SASSAQUI, A.R. Efeitos do Organosuper e do ambiente protegido na formação de mudas de mamoeiro. Engenharia Agrícola, Jaboticabal, v. 31, n.1, p.41-55, 2011.

COSTA, E.; SILVA, P.N.L.; JORGE, M.H.A.; FERREIRA, A.F.A. Guavira emergence and seedling production with substrates containing organic compost and soil under different screen environments. Revista Brasileira de Fruticultura, Jaboticabal, v.34, n.4, p.1289-1293, 2012.
GHORBANI, R.; WILCOCKSON, S.; KOOCHEKI, A.; LEIFERT, C. Soil management for sustainable crop disease control: a review. Environmental Chemistry Letters, v.6, p.149-162, 2008.

KLAFKE, J.Z.; SILVA, M.A.; PANIGASA, T.F.; BELLI, K.C.; OLIVEIRA, M.F.; BARICHELLO, M.M.; RIGO, F.K.; ROSSATO, M.F.; SANTOS, A.R.S.; PIZZOLATTI, M.G.; FERREIRA, J.; VIECILI, P.R.N. Effects of Campomanesia xanthocarpa on biochemical, hematological and oxidative stress parameters in hypercholesterolemic patients. Journal of Ethnopharmacology. v. 127, p.299-305, 2010.

LORENZI, H. Árvores Brasileiras - manual de identificação e cultivo de plantas arbóreas nativas do Brasil. 1.vol. 5.ed. Nova Odessa: Instituto Plantarum. 2008. 384p.

MALAVOLTA, E. Manual de nutrição mineral de plantas. São Paulo: Ceres. 2006. 638p.

MARKMAN, B.E.O.; BACHI, E.M.; KATO, E.T.M. Antiulcerogenic effects of Campomanesia xanthocarpa. Journal of Ethnopharmacology, v.94, p.55-57, 2004.

SILVA, F.C.; EIRA, P.A.; RAIJ, B.V.; SILVA, C.A.; ABREU, C.A.; GIANELLO, C.; PÉREZ, D.V.; QUAGGIO, J.A.; TEDESCO, M.J.; ABREU, M.F.; BARRETO, W.O. Análises químicas para avaliação da fertilidade do solo. In: SILVA, F. C. (Org.). Manual de análises químicas de solos, plantas e fertilizantes. Brasília: Embrapa, 2009. p.75-169.

TAIZ, L.; ZEIGER, E. Fisiologia Vegetal. 5.ed. Porto Alegre: Artmed, 2012. 945p.

VALLILO, M.I.; MORENO, P.R.H; OLIVEIRA, E; LAMARDO, L.C.A.; GABERLOTTI, M.L. Composição química dos frutos de Campomanesia xanthocarpa Berg-Myrtaceae. Ciência e Tecnologia de Alimentos, v.28, p.231-237, 2008.

VINAGRE, A.S.; RÖNNAU, A.D.S.R.; PEREIRA, S.F.; SILVEIRA, L.U.; WIILLAND, E.F.; SUYENAGA, E.S. Anti-diabetic effects of Campomanesia xanthcarpa Berg leaf decoction. Brazilian Journal of Pharmaceutical Sciences, v.46, p.169-177, 2010. 